\title{
Skin Features Score 3
}

National Cancer Institute

\section{Source}

National Cancer Institute. Skin Features Score 3. NCI Thesaurus. Code C131042.

One or more of: deep sclerotic features; hidebound; impaired mobility; ulceration. 